
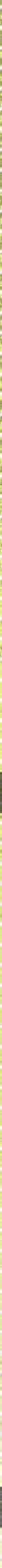


\title{
Vantagens Competitivas Institucionais de Bancos Públicos
}

\author{
Institutional Foundations of Competitive \\ Advantage in Public Bonking
}

* Kurt Mettenheim

\section{Resumo}

Este artigo utiliza conceitos e teorias sobre instituições, falhas de mercado, e bancos para explicar como bancos públicos tendem a superar bancos privados em funções essenciais como o custo de operações, o balanceamento de ativos e passivos, a criação de reservas, a gestão de liquidez, a manutenção da confiança de depositantes e do público em geral, a gestão de problemas relacionados à assimetria de informações, aos custos de agência, ao racionamento de crédito, à drenagem de capital, e outras falhas de mercado e fenômenos importantes de economia política.

Palavras-chave: vantagens comparativas; bancos públicos; bancos privados

\begin{abstract}
This article uses concepts and theories of institutions, market failures, and banks to explain how public banks tend to outperform private banks in essential functions such as cost of operations, balancing of assets and liabilities, creation of reserves, liquidity management, maintaining the confidence of depositors and the general public, and the management of problems related to information asymmetries, agency costs, credit rationing, capital drain, and other market failures and important phenomena of political economy.
\end{abstract}

Keywords: competitive advantages; public banking, private bankings 


\section{Introdução}

B ancos privados procuram maximizar o lucro e manter a governança centrada na livre iniciativa dos executivos e orientada aos acionistas. Em contraste, bancos públicos mantêm modelos de gestão embasados em retornos sustentáveis por horizontes de tempo mais longos, com missões corporativas que incluem políticas públicas, tradições alternativas de governança que priviligiam o controle de executivos pelo conselho do banco, e orientação aos grupos sociais interessados. Desde a liberalização da indústria bancária, o que ocorreu em muitas economias avançadas a partir dos anos de 1980, e em muitos países em desenvolvimento a partir dos anos de 1990, bancos públicos (quando não privatizados), têm se mostrado bancos melhores do que bancos privados em termos de eficiência, rentabilidade, gestão de riscos e outros indicadores de qualidade de gestão bancária (Andrianova, 2012; Ang, 2011; Andrianova etal, 2008; Yeyati etal, 2007). Isto contraria idéias centrais da teoria bancária contemporânea. Também contraria expectativas sobre a superioridade da propriedade privada para a gestão bancária. Porém, a reavaliação de bancos públicos volta aos clássicos como Shonfield (1965) e Zysman (1983) que valorizaram a capacidade de bancos públicos para a reconstrução da Europa depois de 1945 e a gestão de mudança industrial até os anos de 1980.

Abordagens sobre os fundamentos institucionais da vantagem competitiva alargam o campo de análise de bancos porque trazem para o primeiro plano as bases históricas, sociais, políticas e organizacionais das vantagens (como também dos riscos), associados a bancos públicos. Teorias e conceitos sobre instituições extrapolam a visão limitada de bancos como empresas financeiras cujo fim é maximizar o lucro. Como as realidades bancárias envolvem fenômenos sociais e políticos, precisamos nos voltar para os conceitos, métodos e teorias sobre instituições das disciplinas que lhe são pertinenetes, ou seja, de fora da economia. Os instrumentos de análise institucional advindos da sociologia e da ciência política são fundamentais para ampliar o âmbito da investigação para além da teoria bancária contemporânea (Wilson, etal, 2010; Bhattacharya e Thakor, 1993) que insiste em definir bancos como firmas que visam maximizar lucros nas operações dos mercados de capitais.

Paradoxalmente, mesmo os estudos mais críticos dos processos de mudança bancária concordam com as expectativas de convergência para a intermediação financeira, a qual leva ao fim da atuação tradicional de bancos alternativos, ou seja, a instituições que atuam como bancos públicos e cooperativas de crédito. Desse ponto de vista, o foco em bancos que atuam em centros financeiros acaba por dominar em demasiado o debate sobre bancos e sistemas bancários em geral. Portanto, precisamos olhar para além da atuação de atividades daqueles grandes bancos centrados em mercados de capitais (Howard e Hardie, 2013; Admati e Hellwig, 2013), aqueles que são 'too big to fail'; ou ainda focar em processos de desintermediação como evidência de convergência de bancos e sistemas bancários (Allen and Gale, 2000; Schmidt etal, 2001). 
Lembremos, que, tradicionalmente, bancos foram vistos como instituições que aceitam depósitos e fazem empréstimos (Baltensperger, 1980). Assim, bancos permaneciam diferentes de outras empresas em termos das características de seus ativos, passivos, governança, gerenciamento de risco, e desempenho. Porém, desde os anos de 1980, a teoria bancária contemporânea redefiniu bancos como empresas especializadas na intermediação financeira entre clientes e mercados financeiros. A Tabela 1 enumera sete diferenças entre a teoria bancária contemporânea predominante que vê bancos como empresas financeiras e a teoria institucional (e tradicional) aqui retomoda que traz diferentes conceitos e teorias para a análise dos bancos. A teoria bancária contemporânea enfatiza a governança pelos acionistas, a maximização do lucro, a fabricação de ativos financeiros, as estratégias de alta alavancagem e alto risco, os métodos quantitativos de gestão de risco nos mercados financeiros eficientes, as bases teóricas nos preceitos da intermediação financeira, e apresenta, finalmente, expectativas de que todos os bancos convergiriam em direção às práticas mais eficientes dos bancos privados atuando diretamente como intermediários entre cidadãos-investidores e os mercados de moeda e capital.

Tabela 1 - Bancos como instituições versus firmas financeiras

\begin{tabular}{l|l|l}
\hline & Firmas financeiras & Instituições \\
\hline Governança & Acionista & Stakeholders \\
\hline Missão & Lucro & Sustentar retornos e política pública \\
\hline Modelo de Negócios & Fabricação de ativos & Balancear passivos e ativos \\
\hline Estratégia & Maximizar alavancagem & Moderar alavancagem \\
\hline Gestão de Risco & VaR ou modelos quanti & Relacionamento e info complexa \\
\hline Base Teórica & Intermediação financeira & Incerteza e instituições \\
\hline Previsão & Convergência & Variedade persistente \\
\hline
\end{tabular}

Em contraste, a teoria de banco institucional enfatiza a governança pela incorporação de grupos sociais interessadoss no conselho do banco; a produção de retornos sustentáveis ao longo do tempo; o balançeamento tradicional e mais conservador dos ativos e passivos; a restrição de alavancagem a niveis moderados; o uso de informações contextuais e de relacionamento social e bancário; a realidade de incerteza; e teorias de instituições que informam expectativas de que a variedade persistirá no setor bancário, em vez da convergência para o padrão de bancos, típicos de centros financeiros e monetários.

A teoria institucional promete trazer novas perspectivas sobre problemas centrais na análise de bancos. Estudos de caso, análises histórico-institucionais, e comparações de grandes bancos públicos podem melhorar a compreensão do comportamento de bancos, públicos e privados. Estudos de caso e n comparações focalizadas prometem explicar melhor como os bancos públicos alinham os incentivos de proprietários 
(ou seja, governos), gerentes, e funcionários através de culturas corporativas que vão muito além da maximização do lucro. Os métodos de estudos institucionais e organizacionais de pesquisa ajudam a explicar como os bancos desenvolveram mecanismos para reduzir os custos de agência e custo de transação. Os dados sobre os balanços dos bancos, que estão cada vez mais disponíveis de bancos e autoridades monetárias, também oferecem oportunidades para explicar tanto a origem e a evolução dos bancos no passado, como também as transformações atualmente em curso, especialmente no contexto atual de adaptação às novas tecnologias de informação e de comunicação que reduziram o custo de produtos e serviços bancários a menos de um porcento do custo anterior.

A grande escala de muitos bancos públicos também permite usar o foco institucional para examinar como se dão os empréstimos anticíclicos e do papel de bancos públicos em absorver choques. Isto é uma vantagem analítica. Grandes bancos servem como bons estudos de caso ao nível de análise micro ou organizacional. Mas, o tamanho maior de boa parte dos bancos públicos significa que os efeitos de seu comportamento individual são, frequentemente, sentidos nos niveis de análise mezzo e macro. Por exemplo, hoje, décadas após a liberalização do mercado bancário na Índia, o State Bank of India ainda mantém em torno de 85 porcento dos mercados de crédito, como também boa parte dos outros serviços bancários no país. Desta maneira, estudos de caso de bancos públicos servem também para evitar falhas em estudos que comparam dados agregados.

Desde a revolução na tecnologia da informação e a liberalização de setores bancários, houve uma modernização de instituições bancárias tradicionais, em um processo de'volta ao passado' de vários tipos e de várias maneiras (Mettenheim, 2013). Em vez de convergência para bancos privados que centram sua atuação de forma direta entre os cidadãos e os mercados de moeda e de capital, uma ampla variedade de instituições bancárias persistiu, incluindo desde bancos de desenvolvimento ou de propósito específico (Aghion, 1999; Diamond, 1957), a bancos de poupança de governos locais, regionais e nacionais (Ayadi etal, 2009), como também novas instituições de investimento de longo prazo. Isto ocorre não somente desde a liberalização da indústria, mas também desde a crise financeira global de 2007-8.

Neste sentido, ambos os estudos críticos de bancos e a teoria bancária contemporânea incorreram em uma grave falha: a de elevar as práticas tradicionais de bancos privados em centros financeiros para uma teoria universal. Isto acaba por ignorar a variedade institucional maior de tipos de bancos, sejam bancos públicos, sejam cooperativas de crédito, sendo que estas últimas, em muitos países, também continuam a fornecer grande parte do crédito.

Desta maneira, a teoria institucional pode ajudar a renovar a micro e a macroeconomia de estudos bancários, capturarando uma gama maior dos fenômenos que redefiniram a indústria durante as últimas décadas. A teoria institucional também pode aprofundar a compreensão do cenário mais amplo de bancos, especialmente 
em temas como seus papéis anticíclicos, a fim de evitar tanto a formação de bolhas de ativos, como também amenizar as recessões quando elas estouram. Assim, teorias de bancos, se usadas como instrumentos de política pública, acabam também por afastar acusações infundadas de ineficiência do setor bancário, para explicar como os bancos públicos podem multiplicar fundos de governo para superar as restrições fiscais, além de ajudar a melhorar o controle contratual e a accountability durante a implementação de políticas públicas. Além disso, a teoria bancária institucional também pode ampliar a visão da inclusão financeira para além do viés empresarial no mercado de microfinanças, que hoje privilegia o capital privado e ignora tanto a atuação de bancos públicos em países em desenvolvimento, como as experiências positivas do passado de bancos sociais nas economias avançadas.

Para a teoria bancária contemporânea, a eficiência dos mercados levará os mercados de capitais a fornecer produtos e serviços bancários melhor que práticas bancárias tradicionais baseadas em relacionamento com clientes e partes interessadas em instituições sociais e políticas. Aqui, sugerimos o contrário: desde a liberalização da índústria, e durante a adoção de novas tecnologias que transformaram os produtos e serviços bancários, bancos públicos usaram bases institucionais para realizar uma gama notável de vantagens competitivas sobre bancos privados. Mesmo sendo crítica, a teoria de repressão financeira reconhece que o custo operacional e o acesso ao capital barato apresentam vantagens para bancos públicos, pois a lógica básica de 'crowding out' é que o financiamento mais barato e os prazos maiores dos bancos públicos distorcem os preços e inibem o crescimento dos mercados de capital (Gurley e Shaw, 1974).

A teoria institucional de bancos aprofunda esta observação da teoria de repressão financeira com a seguinte resalva. Os bancos públicos foram criados, historicamente, para reparar falhas de mercado e financiar projetos de infraestrutura, de habitação, de agricultura e de outros setores, justamente porque não tinham acesso a crédito a preços e termos oferecidos de bancos privados ou de mercados de capital e moeda. Isto é uma vantagens competitiva dos bancos públicos, isto é poder melhor balancear passivos e ativos, o que permite a transformação de maturidades (de passivos em ativos) em grande escala, aumenta a confiança e a reputação organizacional de bancos públicos, melhora controles internos devido a menor pressão para maximizar lucros; melhora a supervisão interna (o que evita a exposição excessiva de riscos e os fortes incentivos do marketing e vendas não éticas).

A maioria das comparações de desempenho de tipos diferentes de bancos utiliza conceitos e medidas da teoria da agência que enfatizam os acionistas, o uso de controle contratual, e a disciplina do mercado como instrumento interno de gestão. Desta perspectiva, a eficiência de um banco depende da sua capacidade de mitigar potenciais conflitos de agência. Aqui, as teorias neoclássicas sobre a firma como maximizador de lucro dominaram o debate (Fama, 1980). Uma avalanche de análises de dados agregados reportaram evidências, hoje já colocadas em cheque, das 
supostas vantagens universais dos bancos privados sobre os banco públicos, e dos vícios que estes últimos tenderiam a acumular (La Porta etal, 2002).

Contudo, pesquisadores mais céticos focalizaram em problemas inerentes aos bancos privados. Conceitos como rent-seeking e outros comportamentos internos perversos (Fama e Jensen, 1983b; Hart e Moore, 1990) sugerem que a dispersão da participação acionária não consegue evitar que os gestores perseguem seus próprios interesses e não os dos acionistas.

Bancos públicos possibilitam mecanimos de controle internos diferentes dos utilizados em bancos privados. Uma vasta literatura sobre finanças corporativas e teoria da agência enfatiza que contratos podem alinhar os interesses de gestores com os interesses dos acionistas (Jensen e Zimmerman, 1985). Mas os sistemas de remuneração por desempenho aumentam o interesse e a capacidade dos executivos de abusarem de seus cargos e escaparem do controle dos acionistas. Antes da crise financeira global de 2007-2008, as evidências sobre a eficácia de esquemas de pagamento por desempenho (especialmente dos planos de opções de ações) em mitigar conflitos de agência eram, na melhor das hipóteses, ambíguas (Polo, 2007; John e Qian, 2003; Bebchuk e Fried, 2003). A partir da crise de 2007-2008 as evidências são mais claras, mostrando que os gerentes de bancos repetidamente colocaram em perigo suas instituições, prosseguindo com estratégias de alto rendimento e alto risco (Sorkin, 2010). Isto ocorreu a tal ponto que os regimes de remuneração de executivos em grandes bancos privados tornaram-se uma questão política fundamental para nossa época pós-crise.

Bancos públicos dependem de diferentes mecanismos para disciplinar os gestores. Os seus mandatos políticos, sociais, e de implementação de políticas públicas produzem diferentes culturas corporativas e incentivam gestores a trabalhar mais responsavelmente. Em bancos públicos os investidores também retêm interesses com perfil mais concentrado do que o de proprietários de bancos privados, que são acionistas mais dispersos. Os governos (como investidores) têm perfis diferentes, graus de aversão aos riscos maiores, e horizontes de tempo mais longos do que os investidores privados. Como gerentes de bancos públicos que atuam na esfera pública e são responsáveis pelo interesse público, os governos têm menos incentivos e menos oportunidades para ir contra os interesses das partes interessadas. Ligações mais estreitas entre as partes interessadas e os gestores, como também mais e maiores prerrogativas do controle exercido por órgãos sociais, sugerem que bancos públicos são centrais para a coordenação de economias avançadas e em desenvolvimento (Mettenheim, 2010; Hackethal etal, 2005; Hall e Soskice, 2001).

Os custos de conflitos de agência entre depositantes e gestores também tendem a ser muito inferior em bancos públicos, devido ao nível mais elevado de confiança depositada nestas instituições tanto por clientes como pelo público em geral (Grossl etal, 2013). Isto é especialmente verdade em tempos de crise. Em tempos difíceis, os bancos públicos são considerados mais "seguros e com melhores margens" (Dietrich 
e Wanzenried, 2011, p. 321). A maior confiança dos depositantes e do público em geral em bancos públicos se deve, em grande parte, às histórias institucionais, com enraizamentos tanto na sociedade, como na política local, regional e nacional. A governança corporativa orientada para as partes interessadas, a reputação corporativa com base em missões sociais e políticas públicas e, no passado, a garantia de pequenos depósitos em bancos de poupança foram fundamentais para o desenvolvimento desta confiança. De fato, em meio a crises, até hoje depositantes muitas vezes tiram seus fundos de bancos privados para depositar em bancos públicos. Isto reforça ambos os pontos fracos 'pró-cíclicos' de bancos privados, como também a capacidade contracíclica dos bancos públicos (Schclarek-Curutchet, 2014; Mettenheim, 2010).

Para a teoria bancária contemporânea, assimetrias de informação e outras falhas de mercado ajudam a explicar uma variedade de fenômenos na atividade bancária. Sabendo mais sobre os credores, os gestores de bancos privados podem acabar se comportando de forma oportunista para produzir o risco moral, aumentar o risco de crédito e corroer ativos com empréstimos non-performing. A falta de informação sobre clientes ou bairros pode produzir uma seleção adversa, com o racionamento de crédito em bancos privados (Stiglitz e Weiss, 1981). Uma maneira de reduzir as assimetrias de informação e falhas de mercado, neste sentido, é relacionamento bancário, com clientes e com as partes interessadas. Booth define relacionamento bancário como

a prestação de serviços financeiros por um intermediário financeiro que: (i) investe na obtenção específica informação sobre o cliente, muitas vezes de natureza proprietária, e (ii) avalia a rentabilidade destes investimentos através de múltiplas interações com alguns clientes ao longo do tempo e ou através de produtos (Booth, 2000:10).

O relacionamento bancário melhora o intercâmbio de informações e os contratos entre os bancos e os usuários de forma a aumentar a oferta de crédito (Petersen e Rajan, 1994), como também a reduzir as exigências de garantias e custos decorrentes de dificuldades financeiras (Hoshi, Kashyap, e Scharfstein, 1990).

Os bancos públicos estão excepcionalmente bem posicionados para colher as vantagens competitivas do relacionamento bancário. As caixas econômicas regionais e locais estão mais próximas de depositantes e tomadores de empréstimos. São enraizadas em comunidades locais e mantêm redes grandes de agências bancárias. As informações 'soft' recolhidas ao longo do tempo em proximidade com clientes e cidadãos são uma das principais fontes de vantagem competitiva para os bancos públicos. Em comparação, os bancos privados tendem cada vez mais a usar informações muito limitadas a partir de bancos de dados agregados padronizados (Ayadi et al, 2010; Fonteyne, 2007; Cuevas e Fischer, 2006).

Carnevali (2005) argumenta que a presença local de bancos de poupança europeus apresentam vantagens competitivas, pois tornam estas instituições mais capazes de fornecer empréstimos contracíclicos para ajudar familias e firmas a atravesar recessões e ajustes econômicos. 
Com menos pressão para pagar dividendos aos acionistas, os bancos públicos estão mais livres para usar lucros retidos para financiamento. Os bancos de desenvolvimento e bancos para fins especiais podem receber infusão de capital ou depósitos de fundos oficiais de pensão e de poupança. Estas diferentes fontes de financiamento fornecem aos bancos públicos vantagens competitivas sobre os bancos privados e vantagens comparativas para a política social e pública. Isto contraria idéias centrais sobre a repressão financeira que dita que o menor custo de capital para bancos públicos acaba por expulsar os bancos privados do mercado de crédito e distorce os preços do mercado de capitais. No entanto, tendo em conta a gravidade das restrições fiscais de governos, bancos públicos fornecem uma alternativa muito atraente para a despesa pública. Se bancos multiplicam dinheiro, bancos públicos multiplicam o dinheiro público, além de aumentarem o controle contratual sobre a implementação de políticas públicas (Mettenheim, 2010).

Giannola (2009) argumenta que, devido ao fato de que bancos públicos acumularam maiores reservas de capital através de políticas mais cautelosas, estas instituições mantêm uma 'vantagem patrimonial' durante a transição para os acordos de Basiléia. Antes da crise, Fonteyne (2007) previu que o custo de capital para os bancos diminuiria ao ponto de se tornar irrelevante como parte dos custos de operações bancárias. Ao contrário, os custos exorbitantes de recapitalizar bancos privados no mundo inteiro, desde a crise de 2007, tanto como exigência regulamentar ou como estratégia de prudência, sugerem que o acesso a capital de baixo custo continua a ser um elemento fundamental e uma fonte de vantagem competitiva para os bancos públicos sobre bancos privados.

Em comparação, os imperativos da maximização do lucro em bancos privados servem de forte incentivo contra a necessidade, amplamente reconhecida, de reduzir a alavancagem ou, dito de outra maneira, de manter níveis mais seguros de reservas contra os riscos (Lall, 2012). Isto, porque a capitalização de bancos privados aumenta o denominador sobre o qual o retorno bancário é calculado, ou seja, o valor de ações e reservas sobre retornos. Aqui fica aparente uma das anomalias mais gritantes das teorias sobre as virtudes de bancos privados: desde a liberalização da indústria, bancos públicos reportam retornos maiores e mais sustentados do que bancos privados.

Estas diferenças entre bancos públicos e privados no micro somam a diferenças no macro. Primeiro, os bancos públicos ajudam a suavizar riscos intertemporais, uma função central de sistemas bancários. Allen e Gale (1997 e 2000) argumentam que uma das principais vantagens dos bancos sobre os mercados de capitais é sua capacidade de suavizar o risco intertemporal. Bancos são capazes de acumular capital em tempos bons e usá-lo em tempos ruins. Como Ayadi et al apontam 'criando e desbloqueando reservas é uma técnica específica de gestão de riscos' (2010:108). Isto amplia a tese de criação de liquidez (Diamond e Rajan, 2000), de acordo com a qual o acesso ao refinanciamento a baixo custo e a capacidade de bancos para fazer cumprir o reembolso ou liquidar empréstimos ruins são determinantes da função de criação de liquidez dos 
bancos. Isto reforça a importância de nossa observação sobre a maior confiança de clientes e cidadãos em bancos públicos, o que proporciona uma vantagem sobre os bancos privados. Enquanto os clientes tendem a retirar depósitos de bancos privados durante as crises, os depósitos aumentam frequentemente em bancos públicos durante tempos difíceis. Isto reforça a capacidade de bancos públicos em fornecer empréstimos anticíclicos. Assim sendo, os bancos públicos se tornam mais capazes para cumprir a função crítica de suavização de risco intertemporal (Ayadi et al., 2010).

O reconhecimento das vantagens competitivas dos bancos públicos evidencia uma anomalia da teoria contemporânea de bancos e da teoria liberal e neoclássica em geral. Vistos em geral como anacronismos em meio a reformas pró-mercado desde a década de 1980, grandes grupos de bancos públicos têm, no entanto, realizado um bom desempenho desde liberalização, desregulamentação, privatizações, e a adoção de novas tecnologias, mesmo com a crise de 2007-2008.

Em termos semelhantes à redescoberta e reinterpretação das tradições heterodoxas de teorias da firma que vieram melhorar o entendimento de firmas em geral, como entidades inseridas em realidades sociais, políticas e governamentais mais amplas (Biondi et al., 2007), podemos concluir que novas teorias institucionais de bancos são necessárias para explicar o comportamento dos bancos e, especificamente, seu desempenho como parte das realidades sociais, políticas, culturais e econômicas que determinam vantagem competitiva em muitos mercados e esferas em que os bancos alocam recursos.

\section{Da teoria à evidência: Comparando bancos públicos e privados}

Nesta segunda parte do artigo utilizamos dados de portfólio de bancos coletados pelo banco de dados Bankscope para comparar bancos privados e bancos públicos em cinco regiões mundiais em termos de 36 indicadores de performance bancário de 2006-2013. Testes de retornos, qualidade de ativos, capital, custo de operações, e liquidez sugerem a realização de vantagens competitivas de bancos públicos sobre bancos privados conforme discutido, em teoria, na primeira parte deste artigo. $\mathrm{O}$ período dos dados, de 2006-2013, cobre a atuação de bancos antes, durante, e depois da crise global de 2007-2008. Ao contrário da maioria das análises de bancos públicos, evitamos a agregação de dados de indicadores econômicos e sociais na expectativa de isolar o impacto causal destas instituições, as com comparações a seguir focalizam os portfólios de bancos em amostras regionais para captar o comportamento diferenciado de bancos públicos e bancos privados na Europa, América latina, Europa oriental, países da ex-União Soviética, e Ásia sugerem um quadro favorável para atuação dos bancos públicos.

A amostra de bancos para estas comparações de testes de performance de portfólio e retornos inclui um total de 10,805 bancos; 225 bancos públicos e 10,480 bancos privados na Europa (797 privados 70 públicos) Europa oriental (357 privados 
e 17 públicos), a ex-União Soviética (1,190 privados e 14 públicos), a América Latina (556 públicos e 39 privados), e a Ásia (796 privados e 85 públicos). Muito dos trinta e seis indicadores de performance bancário que são disponíveis no banco de dados Bankscope permanecem enviesados em favor do tipo de estrutura e perfil de operações de bancos privados. Há necessidade de aprofundar a discussão sobre os indicadores mais adequados para medir o impacto de bancos públicos, como também de cooperativos e outros tipos de bancos alternativos, ou seja, os bancos não privados. Porém, neste artigo utilizamos estes indicadores de padrão que possam servir de teste inicial, inclusive mais severo e mais difícil para os bancos públicos, para desvendar os críticos e o senso comum contra bancos públicos (ECB, 2010).

O primeiro teste que utilizamos para comparar bancos públicos com bancos privados é dos retornos sobre ativos, talvez o indicador mais comum que é usado para avaliar a competitividade de bancos. Nas amostras regionais do Bankscope, bancos públicos reportaram níveis de retornos sobre ativos maiores que bancos privados. Tabela 2 reporta as médias e os desvios padrões de retornos de bancos privados e de bancos públicos para as amostras de cinco regiões mundiais. Para a amostra de Europa, bancos públicos reportam retornos maiores que bancos privados para os anos que seguem a crise de 2007 (com exceção de 2013) e níveis semelhantes antes os anos da crise. Os bancos públicos nas outras áreas são maiores ou semelhantes que bancos privados, a não ser na amostra da Europa oriental.

Tabela 2 - Retorno sobre ativos em bancos públicos e privados, cinco regiões 2006-2013.

\begin{tabular}{|c|c|c|c|c|c|c|c|c|}
\hline & 2006 & 2007 & 2008 & 2009 & 2010 & 2011 & 2012 & 2013 \\
\hline \multicolumn{9}{|l|}{ Europa } \\
\hline \multirow[t]{2}{*}{ Privado } & 1,27 & 1,27 & 0,39 & 0,26 & 0,15 & 0,12 & 0,41 & 0,32 \\
\hline & 3,94 & 4,83 & 3,63 & 4,24 & 10,03 & 2,66 & 3,78 & 0,49 \\
\hline \multirow[t]{2}{*}{ Público } & 1,00 & 1,22 & 0,13 & 0,40 & 0,71 & 0,26 & 0,48 & $-0,29$ \\
\hline & 1,99 & 3,14 & 1,62 & 1,47 & 2,55 & 2,17 & 1,87 & 1,88 \\
\hline \multicolumn{9}{|c|}{ Europa oriental } \\
\hline \multirow[t]{2}{*}{ Privado } & 1,43 & 1,42 & 0,68 & $-1,09$ & $-1,04$ & $-0,08$ & $-0,07$ & 0,23 \\
\hline & 2,45 & 2,91 & 3,90 & 11,29 & 14,14 & 4,31 & 3,77 & 3,69 \\
\hline \multirow[t]{2}{*}{ Público } & 1,32 & 0,77 & 0,20 & $-1,46$ & $-1,37$ & $-1,67$ & $-2,23$ & \\
\hline & 1,69 & 0,34 & 0,22 & 2,64 & 2,97 & 3,57 & 2,86 & \\
\hline \multicolumn{9}{|c|}{ Ex-União Soviética } \\
\hline \multirow[t]{2}{*}{ Privado } & 2,03 & 2,04 & 1,50 & 0,76 & 1,45 & 1,57 & 1,42 & 1,55 \\
\hline & 2,34 & 4,48 & 4,72 & 5,08 & 4,28 & 3,37 & 3,12 & 4,21 \\
\hline \multirow[t]{2}{*}{ Público } & 1,75 & 2,14 & 2,06 & 0,60 & 0,43 & 1,07 & 1,49 & 1,67 \\
\hline & 0,81 & 0,92 & 2,47 & 1,03 & 1,54 & 1,24 & 2,24 & 1,98 \\
\hline \multicolumn{9}{|c|}{ América Latina } \\
\hline \multirow[t]{2}{*}{ Privado } & 2,00 & 1,73 & 1,14 & 1,38 & 1,46 & 1,17 & 1,30 & 1,63 \\
\hline & 4,09 & 5,31 & 5,42 & 3,84 & 3,58 & 5,17 & 3,71 & 2,01 \\
\hline \multirow[t]{2}{*}{ Público } & 1,45 & 1,72 & 1,80 & 1,33 & 1,80 & 1,80 & 1,84 & 0,60 \\
\hline & 1,79 & 0,81 & 1,25 & 0,96 & 0,99 & 1,23 & 1,05 & 0,18 \\
\hline \multicolumn{9}{|l|}{ Ásia } \\
\hline \multirow[t]{2}{*}{ Privado } & 0,85 & 0,86 & 0,61 & 0,80 & 0,86 & 1,09 & 0,99 & 1,81 \\
\hline & 1,57 & 1,78 & 3,86 & 2,20 & 3,87 & 2,15 & 1,95 & 1,12 \\
\hline \multirow[t]{2}{*}{ Público } & 0,88 & 0,97 & 0,67 & 0,92 & 0,89 & 1,04 & 0,69 & 2,02 \\
\hline & 2,11 & 1,21 & 1,27 & 0,66 & 1,01 & 0,64 & 1,55 & 1,04 \\
\hline
\end{tabular}

Fonte: Bankscope.

Nota: Primeiras linhas em fonte maior $=$ percentagem, segundas linhas $=$ desvio padrão. 
O segundo teste que reportamos aqui para comparar bancos públicos e bancos privados é o valor de renda produzido antes de impostos como porcentagem de ativos totais. Esta segunda medida de retornos produzidos pelos bancos serve de controle para o resultado acima de retornos sobre ativos, como também ajuda a controlar por eventuais diferenças entre bancos devido a diferentes padrões de tributação entre bancos. Em termos de renda antes de impostos como porcentagem dos ativos totais, bancos públicos também produzem, sistematicamente, níveis maiores de renda que bancos privados, a não ser em alguns anos, marcadamente para a amostra de 2013 para a Europa.

Tabela 3 - Renda antes de impostos / ativos totais em bancos públicos e privados, cinco regiões mundiais 2006-2013.

\begin{tabular}{|c|c|c|c|c|c|c|c|c|}
\hline & 2006 & 2007 & 2008 & 2009 & 2010 & 2011 & 2012 & 2013 \\
\hline \multicolumn{9}{|l|}{ Europa } \\
\hline \multirow[t]{2}{*}{ Privado } & 1,39 & 1,25 & 0,55 & 0,45 & 0,51 & 0,43 & 0,26 & 0,46 \\
\hline & 2,08 & 3,07 & 2,52 & 3,11 & 3,19 & 2,70 & 2,46 & 0,70 \\
\hline \multirow[t]{2}{*}{ Público } & 1,34 & 1,32 & 0,31 & 0,80 & 1,07 & 0,66 & 0,87 & $-1,01$ \\
\hline & 2,36 & 2,49 & 2,43 & 1,94 & 3,19 & 1,75 & 2,41 & 2,67 \\
\hline \multicolumn{9}{|c|}{ Ex-União Soviética } \\
\hline \multirow[t]{2}{*}{ Privado } & 3,10 & 3,26 & 2,62 & $-1,19$ & 0,94 & 0,97 & 1,85 & 3,44 \\
\hline & 3,02 & 2,70 & 5,11 & 9,28 & 3,17 & 2,91 & 3,40 & 0,36 \\
\hline \multirow[t]{2}{*}{ Público } & 2,33 & 2,73 & 1,95 & 0,01 & 0,22 & 0,96 & 1,26 & \\
\hline & 1,02 & 1,34 & 1,82 & 1,17 & 2,29 & 0,74 & 0,69 & \\
\hline \multicolumn{9}{|c|}{ América Latina } \\
\hline \multirow[t]{2}{*}{ Privado } & 1,11 & 1,96 & 1,47 & 1,76 & 1,90 & 1,92 & 1,79 & 2,14 \\
\hline & 25,27 & 5,82 & 7,34 & 5,23 & 4,00 & 2,61 & 5,00 & 2,67 \\
\hline \multirow[t]{2}{*}{ Público } & 2,11 & 2,08 & 2,13 & 2,12 & 2,59 & 2,52 & 2,71 & 1,04 \\
\hline & 1,12 & 1,04 & 1,41 & 1,50 & 1,56 & 1,78 & 2,01 & 0,06 \\
\hline \multicolumn{9}{|l|}{ Ásia } \\
\hline \multirow[t]{2}{*}{ Privado } & 1,18 & 1,28 & 1,01 & 1,11 & 1,23 & 1,51 & 1,42 & 2,51 \\
\hline & 1,71 & 1,67 & 4,11 & 2,30 & 3,45 & 1,43 & 1,86 & 1,46 \\
\hline \multirow[t]{2}{*}{ Público } & 1,48 & 1,52 & 1,29 & 1,61 & 1,62 & 1,74 & 1,18 & 2,60 \\
\hline & 1,62 & 1,17 & 1,92 & 0,86 & 0,92 & 0,70 & 1,56 & 1,20 \\
\hline
\end{tabular}

Fonte: Bankscope.

Nota: Primeiras linhas em fonte maior $=$ percentagem, segundas linhas $=$ desvio padrão.

O terceiro teste de performance bancário que apresentamos para comparar bancos públicos e bancos privados é o índice de custo-renda (ver tabela 4). Este índice é amplamente aceito como cálculo da eficiência de operações de bancos, pois mede o custo administrativo (em boa parte salários de empregados) dos bancos que é necessário para gerar renda. Para a amostra de Europa, bancos públicos reportam níveis de custo menor que bancos privados, em todos os anos reportados, a não ser 2013. Isto significa que, em media, os bancos públicos são mais eficientes que bancos privados. Os dados das amostras de outras regiões também confirmam esta vantagem competitiva de eficiência para a maior parte dos bancos públicos. De duas, uma; ou os bancos públicos permanecem pelos anos de 2006-2013 abaixo do nível de bancos privados, ou, no caso da mostra de Europa oriental, de reportar níveis decrescentes de custo sobre renda; justamente enquanto bancos privados passaram por um processo de aumentar custos. Isto confirma, em base de dados extraídos de portfólios 
de bancos, a vantagem forte de bancos públicos de desenvolvimento e de propósito especial sobre bancos privados. Isto pelo tamanho muito menor da sua estrutura administrativa, ou seja, as operações centralizadas de bancos de desenvolvimento ao nível de atacado, sem a rede de atendimento e de agências ao nível de varejo que bancos privados precisam manter. Aqui reside a diferença fundamental entre teorias de desenvolvimento e teorias de repressão financeira, pois o último critica a capacidade de bancos de desenvolvimento de oferecer crédito abaixo o nível de custos viáveis para bancos privados.

Tabela 4 - Índice custo-renda em bancos públicos e privados, cinco regiões mundiais 2006-2013

\begin{tabular}{|c|c|c|c|c|c|c|c|c|}
\hline & 2006 & 2007 & 2008 & 2009 & 2010 & 2011 & 2012 & 2013 \\
\hline \multicolumn{9}{|l|}{ Europa } \\
\hline \multirow[t]{2}{*}{ Privado } & 63,71 & 64,13 & 70,02 & 70,50 & 71,51 & 80,01 & 74,12 & 67,54 \\
\hline & 42,97 & 41,01 & 44,62 & 49,69 & 42,40 & 71,22 & 53,72 & 17,51 \\
\hline \multirow[t]{2}{*}{ Público } & 49,05 & 50,80 & 63,63 & 52,78 & 58,96 & 55,84 & 60,94 & 67,00 \\
\hline & 21,43 & 20,76 & 59,76 & 25,81 & 46,26 & 26,22 & 46,63 & 49,64 \\
\hline \multicolumn{9}{|c|}{ Europa oriental } \\
\hline \multirow[t]{2}{*}{ Privado } & 68,52 & 64,05 & 73,31 & 77,08 & 78,00 & 80,81 & 82,45 & 72,80 \\
\hline & 32,92 & 23,77 & 46,37 & 53,98 & 67,72 & 69,88 & 74,95 & 50,01 \\
\hline \multirow[t]{2}{*}{ Público } & 73,40 & 71,35 & 73,27 & 73,08 & 72,51 & 73,55 & 69,71 & \\
\hline & 21,87 & 15,19 & 11,17 & 26,67 & 29,52 & 29,97 & 32,76 & \\
\hline \multicolumn{9}{|c|}{ Ex-União Soviética } \\
\hline \multirow[t]{2}{*}{ Privado } & 64,76 & 64,48 & 85,62 & 87,86 & 86,46 & 85,16 & 83,55 & 90,71 \\
\hline & 18,57 & 18,69 & 22,36 & 19,77 & 19,31 & 19,95 & 25,91 & 13,43 \\
\hline \multirow[t]{2}{*}{ Público } & 59,55 & 55,38 & 57,09 & 69,11 & 62,62 & 64,83 & 63,67 & 82,31 \\
\hline & 27,47 & 15,13 & 30,42 & 23,86 & 23,98 & 20,48 & 25,33 & 21,45 \\
\hline \multicolumn{9}{|c|}{ América Latina } \\
\hline \multirow[t]{2}{*}{ Privado } & 68,64 & 69,74 & 69,36 & 67,52 & 70,37 & 67,21 & 64,33 & 66,43 \\
\hline & 45,91 & 44,46 & 47,48 & 55,97 & 59,04 & 33,25 & 23,95 & 18,92 \\
\hline \multirow[t]{2}{*}{ Público } & 78,06 & 69,32 & 68,85 & 68,58 & 65,33 & 65,12 & 65,33 & 66,44 \\
\hline & 40,68 & 15,17 & 15,35 & 14,05 & 12,23 & 12,29 & 12,60 & 10,01 \\
\hline \multicolumn{9}{|l|}{ Ásia } \\
\hline \multirow[t]{2}{*}{ Privado } & 57,86 & 55,97 & 63,29 & 61,42 & 56,73 & 58,14 & 57,69 & 47,80 \\
\hline & 33,74 & 31,44 & 51,66 & 44,37 & 28,73 & 43,96 & 33,86 & 15,48 \\
\hline \multirow[t]{2}{*}{ Público } & 56,12 & 70,35 & 55,78 & 52,07 & 55,01 & 52,05 & 45,99 & 51,21 \\
\hline & 36,77 & 117,00 & 29,27 & 24,29 & 44,40 & 31,06 & 11,52 & 12,41 \\
\hline
\end{tabular}

Fonte: Bankscope.

Nota: Primeiras linhas em fonte maior $=$ percentagem, segundas linhas $=$ desvio padrão.

O quarto teste de comparação entre bancos públicos e bancos privados é a margem entre juros pagos para depósitos de clientes e juros cobrados para empréstimos aos clientes (ver tabela 5). A margem de juros é uma boa medida da competitividade do mercado de crédito, notoriamente muito alto no Brasil. Esta medida ajuda a controlar pela possibilidade de que bancos públicos reportam retornos maiores por causa de proteção de mercado ou outras barreiras no mercado de crédito. Em termos de margem de juros, bancos públicos sistematicamente reportam os mesmos níveis dos bancos privados ou, na amostra para Europa, as margens de juros de bancos públicos permanecem na metade dos níveis de margens de juros praticados por bancos privados. Isto apresenta mais uma indicação de uma forte vantagem competitiva de bancos públicos sobre bancos privados na Europa. De novo, isto parece especialmente relevante para a experiência brasileira com margens de juros extremamente altos. 
Tabela 5 - Margem de juros em bancos públicos e privados, cinco regiões mundiais 2006-2013.

\begin{tabular}{|c|c|c|c|c|c|c|c|c|}
\hline & 2006 & 2007 & 2008 & 2009 & 2010 & 2011 & 2012 & 2013 \\
\hline \multicolumn{9}{|l|}{ Europa } \\
\hline \multirow[t]{2}{*}{ Privado } & 2,52 & 2,57 & 2,47 & 2,17 & 2,21 & 2,22 & 3,19 & 1,32 \\
\hline & 2,94 & 4,83 & 2,75 & 2,36 & 2,85 & 2,49 & 25,77 & 1,06 \\
\hline \multirow[t]{2}{*}{ Público } & 1,81 & 1,82 & 1,74 & 1,53 & 1,43 & 1,54 & 1,47 & 1,15 \\
\hline & 1,75 & 1,99 & 1,58 & 1,30 & 1,08 & 1,24 & 1,04 & 1,19 \\
\hline \multicolumn{9}{|c|}{ Europa oriental } \\
\hline \multirow[t]{2}{*}{ Privado } & 5,07 & 5,17 & 5,37 & 5,23 & 4,39 & 4,13 & 4,03 & 4,01 \\
\hline & 3,67 & 3,69 & 3,51 & 7,82 & 6,30 & 7,54 & 2,93 & 1,51 \\
\hline \multirow[t]{2}{*}{ Público } & 4,69 & 4,35 & 4,31 & 4,02 & 4,53 & 4,77 & 4,85 & \\
\hline & 3,10 & 2,71 & 2,95 & 2,33 & 3,29 & 3,72 & 4,66 & \\
\hline \multicolumn{9}{|c|}{ Ex-União Soviética } \\
\hline \multirow[t]{2}{*}{ Privado } & 7,01 & 6,80 & 7,68 & 7,48 & 6,44 & 6,29 & 6,77 & 6,62 \\
\hline & 3,71 & 3,57 & 3,61 & 4,54 & 7,94 & 6,29 & 22,17 & 3,52 \\
\hline \multirow[t]{2}{*}{ Público } & 5,85 & 6,40 & 5,80 & 5,84 & 5,27 & 4,95 & 4,30 & 7,43 \\
\hline & 3,72 & 3,48 & 3,63 & 3,78 & 2,95 & 3,01 & 2,10 & 1,58 \\
\hline \multicolumn{9}{|c|}{ América Latina } \\
\hline \multirow[t]{2}{*}{ Privado } & 8,97 & 9,68 & 8,76 & 8,84 & 7,78 & 8,16 & 8,08 & 9,31 \\
\hline & 11,65 & 12,67 & 10,21 & 15,59 & 10,14 & 11,81 & 10,22 & 10,68 \\
\hline \multirow[t]{2}{*}{ Público } & 4,78 & 4,92 & 5,33 & 6,38 & 6,26 & 6,45 & 6,89 & 4,27 \\
\hline & 2,92 & 3,06 & 2,96 & 3,53 & 4,00 & 3,91 & 4,08 & 1,10 \\
\hline \multicolumn{9}{|l|}{ Ásia } \\
\hline \multirow[t]{2}{*}{ Privado } & 2,93 & 3,05 & 3,81 & 3,27 & 3,30 & 3,40 & 3,35 & 4,54 \\
\hline & 3,70 & 3,22 & 8,49 & 3,05 & 2,91 & 3,03 & 3,04 & 2,00 \\
\hline \multirow[t]{2}{*}{ Público } & 3,36 & 3,01 & 2,83 & 2,64 & 2,83 & 3,09 & 3,14 & 5,02 \\
\hline & 1,94 & 1,99 & 2,38 & 2,12 & 2,39 & 1,74 & 1,21 & 0,28 \\
\hline
\end{tabular}

Fonte: Bankscope.

Nota: Primeiras linhas em fonte maior $=$ percentagem, segundas linhas $=$ desvio padrão.

Em resumo, estes três testes de retornos, eficiência operacional, e competitividade sugerem que bancos públicos mantém vantagens competitivas sobre bancos privados. Os testes a seguir ampliam as comparações para medidas de qualidade de ativos, pois a rolagem de dívidas e outras operações duvidosas possam mascarar resultados ruins em bancos, sejam públicos, sejam privados. Comparar a qualidade de ativos é especialmente importante, do ponto de vista da experiência brasileira, pois durante o regime militar de 1964-1985 como também durante o período de caos monetário e transição para a democracia prolongada, bancos de governos estaduais foram usados, notoriamente, para realizar empréstimos que atrasaram em níveis que chegavam a oitenta por cento em alguns portfólios (Mettenheim, 2010).

Assim, comparamos bancos públicos e bancos privados pelo valor de empréstimos atrasados como porcentagem de empréstimos totais para o período de 2006-2013 (ver Tabela 6). Nesta medida de qualidade de ativos, bancos públicos mantém níveis consideravelmente menores de empréstimos ruins em comparação a bancos privados, a não ser na amostra da Europa oriental, em 2006 nos países da ex-União Soviética, e na América latina em 2013. Nos outros anos, e nas amostras de todas as outras regiões do mundo, o nível de créditos ruins permanece mais baixo em bancos públicos. 
Tabela 6 - Empréstimos atrasados como porcentagem de empréstimos totais em bancos públicos e privados, em cinco regiões mundiais 2006-2013.

\begin{tabular}{|c|c|c|c|c|c|c|c|c|}
\hline & 2006 & 2007 & 2008 & 2009 & 2010 & 2011 & 2012 & 2013 \\
\hline \multicolumn{9}{|l|}{ Europa } \\
\hline \multirow[t]{2}{*}{ Privado } & 3,17 & 3,26 & 4,18 & 6,54 & 6,45 & 7,92 & 9,48 & 7,12 \\
\hline & 3,25 & 3,81 & 3,95 & 8,55 & 6,89 & 10,97 & 14,02 & 11,16 \\
\hline \multirow[t]{2}{*}{ Público } & 3,14 & 3,35 & 3,97 & 4,81 & 5,91 & 5,91 & 6,22 & 4,58 \\
\hline & 4,22 & 4,38 & 4,39 & 6,00 & 7,41 & 7,29 & 8,71 & 6,44 \\
\hline \multicolumn{9}{|c|}{ Europa oriental } \\
\hline \multirow[t]{2}{*}{ Privado } & 5,66 & 6,78 & 7,73 & 12,30 & 15,33 & 17,14 & 17,43 & 5,69 \\
\hline & 11,35 & 14,57 & 11,14 & 13,73 & 14,58 & 16,13 & 15,61 & 1,22 \\
\hline \multirow[t]{2}{*}{ Público } & 5,56 & 5,21 & 8,09 & 14,71 & 21,36 & 22,53 & 31,97 & \\
\hline & 6,32 & 5,68 & 5,57 & 9,74 & 10,64 & 5,92 & 9,40 & \\
\hline \multicolumn{9}{|c|}{ Ex-União soviética } \\
\hline \multirow[t]{2}{*}{ Privado } & 2,35 & 2,42 & 3,58 & 6,24 & 6,00 & 5,20 & 4,58 & 3,30 \\
\hline & 3,83 & 5,70 & 6,31 & 8,70 & 11,06 & 10,92 & 9,25 & 4,49 \\
\hline \multirow[t]{2}{*}{ Público } & 19,66 & 4,09 & 8,11 & 7,96 & 8,26 & 7,05 & 5,35 & 2,34 \\
\hline & 39,42 & 4,28 & 11,26 & 4,50 & 4,88 & 5,48 & 3,68 & 0,10 \\
\hline \multicolumn{9}{|c|}{ América latina } \\
\hline \multirow[t]{2}{*}{ Privado } & 6,67 & 6,30 & 6,46 & 5,91 & 3,54 & 3,94 & 4,34 & 2,66 \\
\hline & 13,81 & 13,12 & 12,27 & 14,80 & 4,25 & 7,19 & 8,97 & 3,51 \\
\hline \multirow[t]{2}{*}{ Público } & 6,01 & 5,11 & 4,36 & 4,79 & 4,61 & 4,01 & 4,29 & 2,72 \\
\hline & 5,38 & 4,50 & 3,00 & 3,33 & 3,03 & 2,95 & 3,08 & 1,29 \\
\hline \multicolumn{9}{|l|}{ Ásia } \\
\hline \multirow[t]{2}{*}{ Privado } & 5,52 & 4,34 & 4,42 & 4,08 & 3,44 & 3,55 & 3,50 & 8,20 \\
\hline & 8,51 & 6,95 & 6,53 & 6,54 & 6,11 & 8,26 & 7,20 & 23,73 \\
\hline \multirow[t]{2}{*}{ Público } & 5,13 & 4,77 & 4,55 & 3,88 & 4,50 & 4,54 & 5,14 & 3,68 \\
\hline & 5,93 & 5,54 & 6,14 & 5,83 & 8,87 & 7,95 & 7,88 & 1,17 \\
\hline
\end{tabular}

Fonte: Bankscope.

Nota: Primeiras linhas em fonte maior $=$ percentagem, segundas linhas $=$ desvio padrão.

Outro teste de qualidade de ativos na gestão bancária é o valor de perdas declaradas. Em termos de perdas declaradas como porcentagem de empréstimos totais, bancos públicos também reportam níveis consideravelmente menores que bancos privados, com algumas exceções (ver Tabela 7). Na amostra de Europa para 2013, bancos públicos chegaram a declarar perdas no valor de 0,93 por cento de empréstimos totais, que aproxima aos níveis de bancos privados (de 0,97). Porém, em todos os outros anos de 2006-2013, bancos públicos reportaram muito menos perdas que bancos privados, isto na mostra de Europa. Para as amostras das outras regiões do mundo, bancos públicos declararam menos perdas que bancos privados, a não ser na Europa Oriental e Ásia, e nestes casos em grau menor. Isto contraria a ideia de superioridade de gestão de bancos privados e apresenta mais evidências de vantagens competitivas em bancos públicos.

O último teste para comparar bancos públicos e bancos privados é o valor de capital mantido em reserva contra eventuais perdas de empréstimos ou de financiamentos. Não reportamos o valor de capital como é definido atualmente pelo 'tier um' e 'tier dois' conforme o Banco Internacional de Compensações, no Acordo de Basileia, pois estas medidas de capital permanecem enviesadas. $O$ viés é que reservas de capital são definidas em termos de posições nos mercados de capital. Isto se baseia na nova 
Tabela 7 - Perdas declaradas como porcentagem de empréstimos totais em bancos públicos e privados, em cinco regiões mundiais 2006-2013.

\begin{tabular}{|c|c|c|c|c|c|c|c|c|}
\hline & 2006 & 2007 & 2008 & 2009 & 2010 & 2011 & 2012 & 2013 \\
\hline \multicolumn{9}{|l|}{ Europa } \\
\hline \multirow[t]{2}{*}{ Privado } & 0,09 & 0,16 & 0,15 & 0,39 & 0,40 & 0,37 & 1,03 & 0,97 \\
\hline & 3,40 & 2,40 & 1,76 & 1,87 & 1,96 & 3,23 & 6,67 & 0,86 \\
\hline \multirow[t]{2}{*}{ Público } & 0,59 & 0,49 & 0,06 & 0,07 & 0,14 & 0,11 & 0,39 & 0,93 \\
\hline & 1,52 & 1,87 & 0,78 & 0,80 & 0,64 & 0,69 & 0,67 & 1,30 \\
\hline \multicolumn{9}{|c|}{ North America } \\
\hline \multirow[t]{2}{*}{ Cooperative } & 0,11 & 0,09 & 0,14 & 0,32 & 0,21 & 0,17 & 0,12 & 0,14 \\
\hline & 0,18 & 0,15 & 0,27 & 0,47 & 0,29 & 0,24 & 0,10 & 0,11 \\
\hline \multirow[t]{2}{*}{ Privado } & 0,27 & 0,46 & 1,05 & 2,13 & 1,82 & 1,09 & 0,73 & 0,25 \\
\hline & 0,57 & 0,97 & 1,55 & 2,96 & 2,27 & 1,31 & 0,91 & 0,16 \\
\hline \multicolumn{9}{|c|}{ Europa oriental } \\
\hline \multirow[t]{2}{*}{ Privado } & $-0,03$ & $-0,24$ & $-0,51$ & 2,00 & $-0,09$ & 0,46 & 0,83 & 0,94 \\
\hline & 4,52 & 2,47 & 3,11 & 32,16 & 5,34 & 3,13 & 1,91 & \\
\hline \multirow[t]{2}{*}{ Público } & 0,88 & 0,21 & 0,34 & $-0,69$ & 0,82 & 0,65 & 2,45 & \\
\hline & 0,99 & 0,28 & 0,45 & 2,57 & 3,23 & 0,62 & 3,87 & \\
\hline \multicolumn{9}{|c|}{ Ex-União Soviética } \\
\hline \multirow[t]{2}{*}{ Privado } & 0,50 & 0,05 & 0,20 & 0,99 & 1,94 & 0,67 & 1,19 & \\
\hline & 1,09 & 2,15 & 3,74 & 4,17 & 5,24 & 1,91 & 4,13 & \\
\hline \multirow[t]{2}{*}{ Público } & 0,29 & 1,18 & 0,07 & 0,22 & 0,52 & 0,37 & 0,68 & \\
\hline & 0,44 & 1,99 & 0,09 & 0,30 & 0,58 & 0,29 & 0,51 & \\
\hline \multicolumn{9}{|c|}{ América Latina } \\
\hline \multirow[t]{2}{*}{ Privado } & 3,08 & 3,23 & 3,11 & 2,09 & 1,69 & 1,40 & 1,49 & 0,81 \\
\hline & 8,34 & 19,68 & 12,65 & 5,17 & 3,82 & 3,09 & 3,26 & 1,42 \\
\hline \multirow[t]{2}{*}{ Público } & 4,78 & 3,32 & 0,39 & 0,78 & 1,29 & 1,11 & 0,88 & 0,67 \\
\hline & 9,06 & 6,52 & 0,87 & 1,04 & 1,33 & 1,71 & 1,19 & \\
\hline \multicolumn{9}{|l|}{ Ásia } \\
\hline \multirow[t]{2}{*}{ Privado } & 0,94 & 0,61 & 0,34 & 0,38 & 0,51 & 0,26 & 0,34 & 0,40 \\
\hline & 1,77 & 1,90 & 1,86 & 1,01 & 4,85 & 1,01 & 1,57 & 1,38 \\
\hline \multirow[t]{2}{*}{ Público } & 1,09 & 0,69 & 1,36 & 0,23 & 0,21 & 1,19 & 0,56 & 0,52 \\
\hline & 1,62 & 0,86 & 4,98 & 0,68 & 1,35 & 4,58 & 0,69 & 0,30 \\
\hline
\end{tabular}

Fonte: Bankscope.

Nota: Primeiras linhas em fonte maior $=$ percentagem, segundas linhas $=$ desvio padrão .

forma de atuar de bancos privados nos mercados financeiros (ou seja, a eficiência de mercados de capital permite operar sem reservas no seu sentido tradicional) (Lall, 2010). Por esta razão, reportamos o valor total de capital de reserva, que é uma medida mais tradicional de qualidade de gestão bancário, pois representa o valor de capital mantido em reserva contra eventuais perdas em operações.

$\mathrm{Na}$ amostra de Europa, bancos públicos mantém níveis semelhantes de reservas em comparação a bancos privados, com a exceção do aumento abrupto reportado na amostra de bancos privados para o ano de 2013. Nas outras amostras regionais, bancos públicos ora retêm valores maiores em reserva contra perdas, ou em níveis semelhantes ou ligeiramente mais altas. Isto indica que, em termos de manter capital suficiente em reserva contra eventuais perdas, os bancos públicos, em média, parecem se comportar muito semelhante aos bancos privados.

Em resumo, nesta segunda parte do artigo apresentamos seis indicadores de performance bancário com dados de Bankscope, um banco de dados que contem dados de portfólios, operações, e resultados financeiros de uma amostra significativa de bancos públicos e privados. Isto supera outras comparações de dados agregados 
por pais em termos de mercado de crédito ou outro indicadores de nível de crescimento econômico ou nível de renda agregada que extrapola a esfera de bancos e, portanto, introduz erros variados. Desta maneira evitamos as falhas de agregação que assombra inferências sobre bancos públicos que ameaçam reforçar o senso comum crítica a bancos públicos por observadores e acadêmicos partidários de neoliberalismo, da teoria econômica neo-clássica, e teoria bancária contemporânea que valoriza a atuação de bancos diretamente em mercados de capital.

Tabela 8 - Capital total em bancos públicos e privados, em cinco regiões mundiais 2006-2013.

\begin{tabular}{|c|c|c|c|c|c|c|c|c|}
\hline & 2006 & 2007 & 2008 & 2009 & 2010 & 2011 & 2012 & 2013 \\
\hline \multicolumn{9}{|l|}{ Europa } \\
\hline \multirow[t]{2}{*}{ Privado } & 16,74 & 17,18 & 16,10 & 17,29 & 19,96 & 20,72 & 21,06 & 32,50 \\
\hline & 17,49 & 16,78 & 11,06 & 11,46 & 19,76 & 27,50 & 29,19 & 80,23 \\
\hline \multirow[t]{2}{*}{ Público } & 15,00 & 14,74 & 16,58 & 15,49 & 17,92 & 20,24 & 19,91 & 17,25 \\
\hline & 9,11 & 9,75 & 14,56 & 6,74 & 8,13 & 12,19 & 9,37 & 4,97 \\
\hline \multicolumn{9}{|c|}{ Europa oriental } \\
\hline \multirow[t]{2}{*}{ Privado } & 20,70 & 19,66 & 21,91 & 22,60 & 20,34 & 19,62 & 18,36 & 29,06 \\
\hline & 16,44 & 13,94 & 25,35 & 21,48 & 15,33 & 11,86 & 8,87 & 31,59 \\
\hline \multirow[t]{2}{*}{ Público } & 30,50 & 23,23 & 22,28 & 20,21 & 20,67 & 21,33 & 15,75 & \\
\hline & 23,72 & 18,14 & 14,90 & 11,68 & 10,54 & 14,34 & 4,77 & \\
\hline \multicolumn{9}{|c|}{ Ex-União Soviética } \\
\hline \multirow[t]{2}{*}{ Privado } & 20,84 & 19,97 & 22,16 & 30,16 & 25,61 & 21,74 & 20,94 & 19,20 \\
\hline & 11,27 & 9,40 & 15,93 & 34,42 & 20,50 & 12,91 & 13,07 & 4,40 \\
\hline \multirow[t]{2}{*}{ Público } & 31,45 & 30,08 & 14,83 & 17,56 & 15,36 & 15,85 & 15,99 & \\
\hline & 33,22 & 33,37 & 3,21 & 5,44 & 4,80 & 7,32 & 4,89 & \\
\hline \multicolumn{9}{|c|}{ América Latina } \\
\hline \multirow[t]{2}{*}{ Privado } & 22,03 & 25,09 & 24,65 & 25,35 & 24,23 & 22,53 & 20,87 & 17,17 \\
\hline & 15,85 & 22,22 & 35,83 & 39,58 & 43,28 & 21,25 & 19,05 & 6,25 \\
\hline \multirow[t]{2}{*}{ Público } & 22,08 & 20,01 & 18,16 & 16,53 & 16,91 & 19,88 & 15,54 & \\
\hline & 10,25 & 8,26 & 7,17 & 4,13 & 3,71 & 13,36 & 2,93 & \\
\hline \multicolumn{9}{|l|}{ Ásia } \\
\hline \multirow[t]{2}{*}{ Privado } & 15,92 & 15,83 & 17,55 & 18,45 & 20,37 & 18,24 & 17,77 & 14,08 \\
\hline & 18,50 & 15,11 & 25,24 & 21,01 & 34,09 & 42,30 & 17,96 & 4,60 \\
\hline \multirow[t]{2}{*}{ Público } & 13,74 & 13,59 & 12,89 & 13,53 & 13,14 & 13,12 & 12,60 & 15,62 \\
\hline & 3,70 & 4,66 & 4,67 & 3,84 & 3,92 & 3,37 & 4,57 & \\
\hline
\end{tabular}

Fonte: Bankscope.

Nota: Primeiras linhas em fonte maior $=$ percentagem, segundas linhas $=$ desvio padrão.

\section{Conclusão}

Procuramos reavaliar o papel dos bancos públicos neste artigo. Passou o tempo do consenso de Washington sobre as virtudes da privatização em conjunto com a liberalização. Nesta conclusão, situamos brevemente as ideias e evidências reportadas aqui num contexto maior das pesquisas sobre bancos públicos. Primeiro encontramos, em três estudos de caso dos grandes bancos do governo federal brasileiro, a realização de vantagens competitivas sobre bancos privados e bancos estrangeiros desde a abertura do setor em 1995 (Mettenheim, 2010). Expandimos a análise junto com pesquisadores de outros países que também encontraram processos semelhantes, ou seja, a manutenção ou expansão da presença de bancos públicos nos mercados 
de crédito, finanças e serviços desde a abertura de suas indústrias bancárias locais e regionais (Butzbach e Mettenheim, 2014). Neste artigo procuramos elaborar explicações alternativas com conceitos e teorias institucionais nas ciências sociais desta anomalia para as teorias dominantes, seja na área de estudos bancários aonde a teoria contemporânea bancária (Berger ET al, 2010; Bhattacharya e Thakor, 1993) focaliza exclusivamente bancos privados atuantes nos grandes centros financeiros mundiais; seja nas concepções de bancos como firmas que visam maximizar lucro na tradição neoclássica de economia; seja nas expectativas de políticas neoliberais de convergência para o padrão de bancos privados e estrangeiros (de duas maneiras, ou de vez pelas privatizações ou gradualmente pelas supostas vantagens competitivas de bancos privados e estrangeiros).

Teoria e evidências sugerem a necessidade de repensar bancos públicos. Longe de sempre ser o vilão responsável por subdesenvolvimento e/ou repressão financeira, submetemos que bancos públicos são instituições que refletem trajetórias longas que acumularam tradições ricas de gestão bancária que envolve a integração das operações de bancos junto aos processos sociais e políticos, mas também atento para os problemas fundamentais da atividade bancária. No Brasil, como em boa parte dos outros países, bancos públicos sofreram, de fato, captura. Porém, longe de ser fenômeno de democracia e interesses políticos-eleitorais, lembramos que os piores abusos e desvios de bancos públicos brasileiros ocorreram durante o regime militar (isto, desafortunadamente, é semelhante à ocupação dos bancos públicos por movimentos e regimes fascistas e autoritários no passado de economias avançadas).

$\mathrm{E}$ depois do autoritarismo, veio o neoliberalismo. Portanto, apesar da volta à democracia, as ideologias neoliberais e as teorias neoclássicas se juntaram para promover uma imagem negativa categórica de bancos públicos. Neste artigo, perante as consequências devastadoras da crise financeira global de 2007-2008, esperamos ter contribuído com alguns apontamentos de teoria, de conceito e de evidência para uma agenda de pesquisas menos enviesadas e mais informadas sobre as vantagens competitivas, e riscos, de bancos públicos.

Neste sentido, há agendas ricas para a realização de pesquisas futuras. Temas tais como o racionamento de crédito, a fuga de capitais, a diversidade organizacional dos bancos, a estabilidade de sistemas bancários, o desempenho de bancos nas diversas fases do ciclo de negócios, a resiliência de bancos perante crises financeiras e recessões econômicas, e a transformação de maturidade fornecem, todas, áreas promissoras para elaborar uma teoria institucional mais ampla de bancos públicos. Para isto, será necessário superar os preconceitos de estudos bancários que focalizam exclusivamente os bancos privados, e pior; tratam somente de bancos privados que atuam diretamente em operações de atacado em mercados de capitais. Em seu livro clássico, Comparing Financial Sustems, de 2000, Allen e Gale concluiram preocupados com a possibilidade de que a liberalização de sistemas bancários poderia levar a destruição de grandes instituições bancárias não privados. Pois, para Allen e Gale, 
estas instituições não pareciam capazes, de ponto de vista deles, de enfrentar bancos privados e estrangeiros em mercados bancários abertas para a competição livre.

Um número considerável de bancos públicos foram, de fato, privatizados. Outros bancos públicos abandonaram suas tradições em favor de modelos de negócios e meios de gestão embasados em paradigmas de bancos privados. No entanto, pesquisas recentes mostram como bancos públicos voltaram para suas tradições institucionais para realizar vantagens competitivas sobre os bancos privados. Isto proporciona uma agenda de pesquisa mais positiva que Allen e Gale temiam há 15 anos: bancos públicos oferecem uma oportunidade para desenvolver teorias allternativas institucionais da atividade bancária, agora não como firma financeira privada para maximizar lucro, e sim como agentes no meio de processos sociais, políticos e de gestão de políticas públicas. Isto vale para processos de captura, de rentismo, e da corrupção destas instituições bancárias durante regimes oligárquicos e autoritarios no passado, seja como agentes centrais que surgiram, contra o senso comum, decadas depois da liberalização e da adoção de novas tecnologias que estão revolucionando a sua indústria. Críticos de bancos públicos já enumeraram boa parte de suas falhas. Hoje está na hora de voltar as teorias tradicionais de banco públicos, e de prestar mais atenção às experiências de bancos públicos, brasileiros e internacionais, no passado e no presente, para repensar como estas instituições possam contribuir para o desenvolvimento e o bem estar.

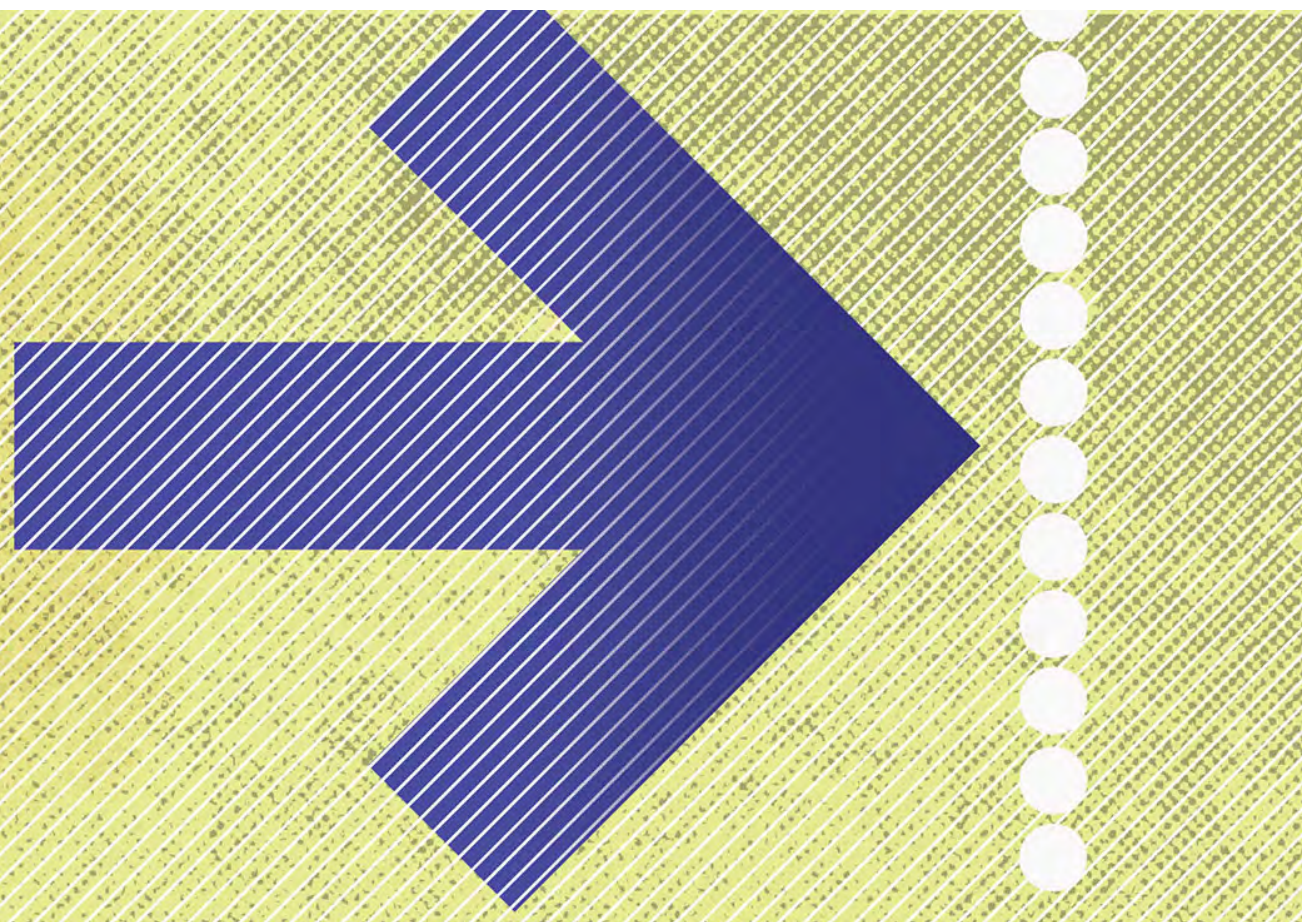




\section{Referências}

ANDRIANOVA, S. 'Public Banks and Financial Stability.' Economic Letters, 116: 86-88

ANDRIANOVA, S., DEMETRIADES, P., e SHORTLAND, A., 2008. 'Government ownership of banks, institutions, and financial development.' Journal of Development Economics, 85: 218-52.

ANG, J. (2011). 'Financial development, liberalization and technological deepening.' European Economic Review,55: 688-701.

AGHION, B.A. (1999), 'Development Banking,' Journal of Development Economics, 58: 83-100.

ADMATI, A. e HELLWIG, M. (2013), The Bankers' New Clothes: What's Wrong with Banking and What to Do About It, Princeton, NJ: Princeton University Press.

ALLEN, F. e GALE, D. (1997), 'Financial Markets, Intermediaries, and Intertemporal Smoothing,' Journal of Political Economy, 105(3): 523-46

ALLEN, F. e GALE, D. (2000). Comparing Financial Systems. Cambridge, MA: MIT press.

AYADI, R., SCHMIDT, R.H. e CARBÒ VERDE, S. (2009), Investigating Diversity in the Banking Sector in Europe: the Performance and Role of Savings Banks, Brussels: Center for European Policy Studies

BALTENSPERGER, E. (1980), 'Alternative approaches to the theory of the banking firm,' Journal of Monetary Economics, 6: 1-37

BEBCHUK, L.A. e FRIED, J. (2006), Pay without Performance: The Unfulfilled Promise of Executive Compensation, Cambridge, MA: Harvard University Press.

BECK, T.H.L., DE JONGHE, O.G. e SCHEPENS, G. (2012) 'Bank Competition and Stability: Cross Country Heterogeneity'Working Paper 85, Tilburg University, Center for Economic Research.

BERGER, A.N., MOLYNEUX, P. e WILSON, J.O.S. (org., 2010), The Oxford Handbook of Banking, Oxford: Oxford University Press

BHATTACHARYA, S. e THAKOR, A. (1993), 'Contemporary Banking Theory', Journal of Financial Intermediation, 3: 2-50

BIONDI, Y., CANZIANI, A. e KIRAT, T. (2007), The Firm as an Entity. Implications for Economics, Accounting, and the Law, Oxon: Routledge.

BOOT, A.W.A. (2000), 'Relationship Banking: What Do We Know?', Journal of Financial Intermediation, 9: 7-25

BRESLER, A., GROSSLE, I. e TURNER, A. (2007). 'The Role of German Savings Banks in Preventing Financial Inclusion'. in Anderloni, L. et al (org). New Frontiers in Banking Services. Berlin: Springer, pp. 247-69

BUTZBACH, O. e METTENHEIM, K. (org). (2014) Alternative Banking and Financial Crisis, London: Pickering and Chatto.

CARNEVALI, F. (2005), Europe's Advantage: Banks and Small Firms in Britain, France, Germany, and Italy since 1918. Oxford: Oxford University Press

CHAKRAVARTY, S.P. e WILLIAMS, J.M. (2006), 'How Significant Is the Alleged Unfair Advantage Enjoyed by State-Owned Banks in Germany?' Cambridge Journal of Economics, 30(2): 219-26.

DIAMOND, D. (1984), 'Financial Intermediation and Delegated Monitoring,' Review of Economic Studies, 51: 728-62.

DIAMOND, W. (1957). Development Banks, Baltimore, MD: Johns Hopkins University Press.

ECB (EUROPEAN CENTRAL BANK). (2010). 'Beyond ROE - How to Measure Bank Performance. Appendix to the report on EU banking structure. Frankfurt, European Central Bank. 
FAMA, E. (1980b), 'Agency problems and the theory of the firm,' The Journal of Political Economy, 88(2): 288-307.

GIANNOLA, A. (2009), 'Origins and evolution of credit,' in Giannola, A. and D'Angelo, G. (org), Financing Enterprises: Basel Il and the changes induced in knowledge, competice and bankenterprise relationship, Naples: Liguori Editore, p. 13-44

GURLEY, J. e SHAW, E. (1960), Money in a Theory of Finance, Washington, DC: Brookings Institute Press.

GRÖSSL, I., VON LÜDE, R. and FLECK, J. (2013). 'Genesis and Persistence of Trust in Banks,' University of Hamburg DEP (Socioeconomics) Discussion Papers, Macroeconomics and Finance Series, 7/2013

HACKETHAL, A., SCHMIDT, R.H. and TYRELL, M. (2005). 'Banks and German Corporate Governance: on the way to a capital market-based system?' Corporate Governance: An International Review, 13(3): 397-407

HAKENES, H. and SCHNABEL, I. (2006). 'The Threat of Capital Drain: A Rationale for Public Banks?' Bonn: Max Planck Institute for Research on Collective Goods, Working Paper 44.

HALDANE, A. G., and MAY, R.M. (2011), 'Systemic risk in banking ecosystems,' Nature, 469(20): 351-55.

HALL, P. e SOSKICE, D. (orgs). (2001). Varieties of Capitalism: The Institutional Foundations of Comparative Advantage. Oxford: Oxford University Press.

HANSMANN, H. (1996), The Ownership of Enterprise, Cambridge, MA: Harvard University Press HARDIE, I and HOWARTH, D. (org). (2013). Market Based Banking and the International Financial Crisis. Oxford: Oxford University Press.

IANNOTTA, G., NOCERA, G. e SIRONI, A. (2007), 'Ownership structure, risk and performance in the European banking industry,' Journal of Banking and Finance, 31: 2127-49

JOHN, K. e QIAN, Y. (2003), 'Incentive Features in CEO Compensation in the Banking Industry,' Federal Reserve Bank of New York Economic Policy Review, 9(1): 109-21.

KLEIN, M. (1971), 'A Theory of the Banking Firm,' Journal of Money, Credit and Banking, 3: 205-18

KÖRNER, T. e SCHNABEL, I. (2011). 'Public ownership of banks and economic growth - the role of heterogeneity.' Economics of Transition, 19 (3): 407-41.

KRAHNEN, J.P. e SCHMIDT, R.H. (orgs). (2004). The German Financial System. Oxford: Oxford University Press.

LALL, R. (2012). 'From failure to failure: The politics of international banking egulation.' Review of International Political Economy, 19(4): 609-38.

LA PORTA, R., LOPEZ-DE-SILANES, F. e SCHLEIFER, A. (2002), 'Government Ownership of Banks,' Journal of Finance 57(1): 265-301

LEVY-YEYATI, E., MICCO, A., e PANIZZA, U. (2007). 'A reappraisal of state owned banks.' Economía 7: 209-59.

METTENHEIM, K. (2010). Federal Banking in Brazil. London: Pickering and Chatto.

MICCO, A. e PANIZZA, U. (2006). 'Bank ownership and lending behavior.' Economic Letters 93, 248-54.

POLO, A. (2007), 'The corporate governance of banks: the state of the debate,'MPRA Paper $n$. 2325.

PROWSE, S. (1997), 'The Corporate Governance System in Banking: What Do We Know?' Banca del Lavoro Quarterly Review (March), 11-40. 
SCHCLAREK-CURUTCHET, A. (2014). 'The Counter-Cyclical Behaviour of Public and Private Banks: An Overview of the Literature,'em Butzbach e Mettenheim, (orgs). Alternative Banking and Financial Crisis, London: Pickering and Chatto, pp. 43-50

SCHMIDT, R.H. (2009): 'The political debate about savings banks,'Schmalenbach Business Review, 61: 366-92

SHONFIELD, A. (1965). Modern Capitalism: The changing balance of public and private power. Oxford: Oxford University Press.

STIGLITZ, J. e WEISS, A. (1981), 'Credit Rationing in Markets with Imperfect Information, American Economic Review 71:353-76

WRAY, L.R. (2013), 'What Do Banks Do? What Should Banks Do? A Minskian Perspective,' Accounting, Economics and Law: A Convivium, 3(3): 277-311.

ZYSMAN, J. (1983). Governments, Markets, and Growth: Financial Systems and Politics of Industrial Change, Ithaca, NY: Cornell University Press.

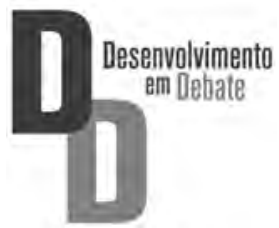

